\title{
Entre os enunciados políticos e os corredores de liberdade nas práticas curriculares dos professores
}

\author{
Carla Figueiredo ${ }^{1}$ \\ ORCID: 0000-0003-3261-4907 \\ Carlinda Leite ${ }^{1}$ \\ ORCID: 0000-0001-9960-2519 \\ Preciosa Fernandes ${ }^{1}$ \\ ORCID: 0000-0002-4318-3308
}

\section{Resumo}

A concretização do princípio de uma educação democrática fundada na igualdade de oportunidades de sucesso para todos tem justificado discursos políticos que, referindo-se à autonomia das escolas e dos professores, reconhecem a importância do seu papel na construção de práticas curriculares adequadas aos diferentes contextos e características dos alunos. No caso dos professores, essa autonomia está associada ao conceito de agência e remete a seu papel ativo, em contexto escolar, na definição e condução dos processos curriculares. Tendo essa perspectiva por referência, este artigo analisa possibilidades e dificuldades que se apresentam aos professores que, diariamente, procuram percorrer os corredores de liberdade curricular e pedagógica. Para isso, foi realizado um estudo que recolheu e analisou discursos de professores de escolas bem colocadas no ranking nacional português sobre as suas práticas curriculares quotidianas, particularmente no que os motiva para o recurso a práticas de contextualização e a factores que influenciam ou impedem o seu desenvolvimento. Conclui-se que a autonomia docente, apesar de presente em orientações políticas, concorre com outras imposições externas que deixam pouco espaço aos professores para desenvolverem práticas curriculares que adequem o currículo prescrito a nível nacional aos contextos escolares reais. Conclui-se igualmente que, apesar das circunstâncias e condicionantes existentes, os professores ouvidos neste estudo procuram espaços e momentos para percorrer os, por vezes estreitos, corredores de liberdade.

\section{Palavras-chave}

Políticas educacionais - Práticas curriculares - Agência dos professores.

1- Universidade do Porto, Porto, Portugal. Contatos: cfigueiredo@fpce.up.pt; carlinda@fpce.up.pt; preciosa@fpce.up.pt.

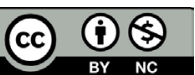




\title{
Between political statements and the "corridors of freedom" in teachers' curricular practices
}

\begin{abstract}
Political discourses advocating for school and teachers' autonomy have been rising concerned with fulfilling the principle of democratic education, based on equal opportunities so everyone can be successful. Regarding teachers, the autonomy is linked with the concept of agency and envisages teachers' active role in the development of curricular processes. Bearing this in mind, this paper analyses the possibilities and difficulties faced by teachers who try to run across curricular and pedagogical "corridors of freedom", on a daily basis. To this regard, a research was conducted by collecting and analysing the opinions of teachers from schools in a high position in the Portuguese national ranking. Opinions focused on teachers' daily curricular practices, particularly their motivation to use them or the aspects that constrain their development. Conclusion was that teachers' autonomy, although present in political guidelines, is in conflict with external demands and impositions that leave little room for devising curricular practices that would adapt the national curriculum to real-life school contexts. Likewise, one concludes that despite of the existing circumstances and constraints, teachers participating in this study are in search for windows of space and time to go through those rather narrow corridors of freedom.
\end{abstract}

\section{Keywords}

Educational policies - Curricular practices - Teachers' agency.

\section{Introdução}

Os contextos educativos atuais apresentam uma complexidade que obriga as escolas e os professores a continuamente repensarem o projeto educativo e curricular que desenvolvem. Métodos e medidas aplicadas indiscriminadamente e sem as devidas adaptações às situações reais e às especificidades dos diversos alunos têm se revelado pouco eficazes ou até prejudiciais. Estudos vários (KALBACH; FORESTER, 2006; PALIWAL; SUBRAMANIAM, 2006; BUSTOS-OROSA, 2008; BUENDÍA; GITLIN; DOUBIA, 2003; KUMAR; NATARAJAN, 2007; DOYLE, 2009) mostram a importância de modos de trabalho pedagógico dos docentes que têm em conta características dos alunos com distintas origens socioeconômicas, diferentes capitais culturais e com interesses e necessidades variadas.

No quadro dessa problemática, intensifica-se a discussão sobre as medidas "one size fits all" (COMISSÃO EUROPEIA, 2017) e apela-se à necessidade de se pensar a educação escolar em contexto. Essa postura exige conhecimento aprofundado das realidades escolares e das condições e potencialidades locais, na sua complexidade e multiplicidade, que apoie 
práticas geradoras de sucesso, não apenas dos alunos, mas da própria educação escolar. Urge repensar a prática docente e a escola tendo em consideração abordagens bottom-up, isto é, que contemplem iniciativas locais e não apenas diretivas emanadas do poder cental (top-down), e que, por isso, possam promover uma ação educativa e pedagógica adequada aos contextos e sua população. Este é um dos argumentos que dá força à medida política de autonomia das escolas, a qual tem conferido aos estabelecimentos escolares e aos seus profissionais alguma, ainda que não muita, margem de liberdade ao nível das práticas curriculares. A autonomia das escolas e dos professores tem feito parte de medidas e discursos políticos por todo o mundo, sobretudo a partir dos anos 1990, acompanhando os ideais de uma educação democrática.

Vários países europeus têm concedido alguma autonomia às escolas nos processos de gestão, incluindo alguma liberdade para a configuração, por parte dos professores, das práticas curriculares (EURYDICE, 2007). Em Portugal, por exemplo, a autonomia das escolas passou a fazer parte dos diplomas legais em 1998 (PORTUGAL, 1998) e, desde então, tem feito parte dos discursos políticos relativos à gestão escolar.

Ampliando os corredores de liberdade a que muitos professores recorrem, na transição do século XX para o XXI, contrariando o sistema fortemente centralizado existente em Portugal, foi instituída a Gestão Flexível do Currículo do Ensino Básico, iniciada em 1997 e reforçada em 1999. Essa medida política visou dotar as escolas e os professores de maior autonomia no desenvolvimento do currículo. Interrompida em 2012, esta orientação curricular que confere poder de decisão às escolas e aos professores, a quem os reconhece na sua agência, parece ser agora (em 2017) recuperada pela atual equipe do Ministério da Educação. Em regime de experiência, foi implementado no ano escolar de 2017-2018 o projeto de autonomia e flexibilidade curricular dos ensinos básico e secundário, que foi depois alargado a todas as escolas em 2018/2019, o que revela, uma vez mais, o reconhecimento, ao nível do discurso político, da importância de se pensar a educação numa perspectiva local, contextualizada, partindo do saber dos professores, do seu conhecimento sobre os contextos e os seus alunos e da sua competência para agir de acordo com esse conhecimento do local e das suas especificidades.

No entanto, estas medidas políticas têm concorrido com outras de natureza mais homogeneizantes que encorajam abordagens curriculares mais tradicionais e transmissivas e nas quais prevalece a comparação entre alunos e os conteúdos por estes adquiridos. Disso são exemplo os exames nacionais que obrigam a práticas docentes direcionadas para a preparação dos alunos para a prova final, cujos resultados permitem depois a construção de rankings de escolas. Essa situação traz uma pressão acrescida na escolha dos processos didáticos a se desenvolver com os alunos, empurrando, muitas vezes, os professores para seguirem o que é definido segundo uma lógica top-down que, forçosamente, ignora as especificidades dos distintos contextos escolares e das populações que os constituem.

Realça-se o fato de que a governação e organização da educação escolar em Portugal, assim como em outros países, têm vivido uma tensão de discursos e de posições que, ao invés de serem complementares, têm se tornado concorrentes, e que opõem o que é enunciado às condições existentes para a sua concretização. 
É esse desfasamento entre discursos políticos e condições para a concretização da prática curricular que se analisa neste artigo. Nele damos conta de uma investigação realizada sobre as práticas docentes de contextualização curricular que permite conhecer o que leva os professores a optarem por esse tipo de estratégias e condições que os influenciam. Com essa investigação, que ouviu vozes de professores, trazemos ao debate acadêmico a importância de reconhecer os professores enquanto agentes educativos com poder de agência.

\section{A agência dos professores nos discursos políticos em Portugal}

0 desenvolvimento de um processo de ensino-aprendizagem contextualizado, que tenha em consideração as especificidades dos contextos e dos sujeitos, remete à noção de agência dos professores (PRIESTLEY, 2011; PRIESTLEY, BIESTA, ROBINSON, 2015). De acordo com Priestley (2011, p. 16), a agência diz respeito à "capacidade de os indivíduos agirem reflexivamente dentro das possibilidades dos ambientes sociais e materiais a fim de promover mudanças nas suas condições”. Essa definição corresponde à "visão ecológica de agência”, defendida por Biesta e Tedder (2007, p. 136) que sublinham que a

[...] agência [...] não é algo que as pessoas possuem; é algo que as pessoas fazem. Denota a "qualidade" do envolvimento dos atores com contextos-de-ação temporais-relacionais, e não uma qualidade dos atores em si.

Os mesmos autores afırmam ainda que não se trata de uma capacidade estanque e aplicável indiscriminadamente em diferentes contextos e tempos. Aplicada ao contexto escolar, a agência remete a uma visão do papel dos professores como profissionais ativos com capacidade para decidir e agir localmente, e refletir sobre as decisões assumidas. Está associada ao conceito de professor como configurador de currículo, que rompe com papéis que o remetem à figura de mero consumidor de um currículo que lhes é prescrito para ser cumprido a nível nacional (LEITE, 2003, 2006; LEITE; FERNANDES, 2010) e que não contempla as realidades locais. Essa é uma característica valorizada na literatura acadêmica que, apoiada em investigações, tem afırmado que o modo como os professores trabalham para dar resposta às necessidades dos seus alunos é essencial ao seu sucesso e formação (YAMAUCHI, 2003; GILLESPIE, 2002; HARTNELL-YOUNG; VETERE, 2008; KALBACH; FORESTER 2006; PALIWAL; SUBRAMANIAM, 2006; BUSTOSOROSA, 2008; BUENDÍA; GITLIN; DOUBIA, 2003; KUMAR; NATARAJAN, 2007; DOYLE, 2009; ZIBETTI; REBELLO DE SOUZA, 2010; FRANCO, 2015; BEANE, 2003). Associada a essas perpectivas, valoriza-se a criatividade que leva os professores a pensarem "fora da caixa" e a promoverem condições e experiências que cortam com práticas tradicionais (ZIBETTI; REBELLO DE SOUZA, 2010). Nas palavras de Grainger, Barnes e Scoffham (2004, p. 252), "professores criativos usam a sua própria criatividade, não apenas para interessar e envolver os alunos, mas também para promover novas aprendizagens e raciocínios”. A criatividade parece, então, ser entendida como uma condição essencial para a realização 
de aprendizagens significativas. Como argumenta Davies (2006, p. 56), os professores que estimulam os alunos para a criatividade e para o desenvolvimento de competências, conhecimentos e valores estarão a promover "um ambiente educativo inclusivo que é genuinamente progressivo, relevante e essencial para construir culturas de confiança e criatividade no ensino-aprendizagem".

Como se depreende, tais procedimentos pedagógico-didáticos têm como matriz um ensino centrado nos alunos, construído a partir de suas características, interesses, necessidades e conhecimentos prévios e que, por essa razão, se torna mais significativo para os alunos reais com que cada professor trabalha (HARTNELL-YOUNG; VETERE, 2008; COOK-SATHER, 2006; SOUTO-MANNING, 2008; KING; BELLOCHI; RITCHIE, 2007; YAMAUCHI, 2003; GILLESPIE, 2002; KALBCH; FORESTER, 2006). Olhando esse modelo pedagógico-didático pelo ângulo dos seus efeitos ao nível das aprendizagens dos alunos, os estudos têm concluído que ele é potenciador da aprendizagem (LEITE; FERNANDES, 2002; HARTNELL-YOUNG; VETERE, 2008; DOYLE, 2009; COOK-SATHER, 2006; SOUTOMANNING, 2008).

Nesta breve sistematização de um referencial teórico que permita analisar como os discursos políticos contemplam o poder de agência dos professores, não se pode ignorar esse poder na configuração de práticas de articulação curricular (LEITE, 2003). Foi isso que Beane (2003) defendeu com a ideia de que a integração curricular é uma forma de tornar o desenvolvimento do currículo mais significativo e democrático e as aprendizagens dos alunos duradouras. Essa ideia remete ao trabalho por temas, e não por disciplinas isoladas, e parece apontar para o sentido de um currículo em que são trabalhadas diferentes temáticas que exigem aprofundamento de conteúdos de natureza diversa (FORMOSINHO; MACHAD0, 2008). Estes e outros exemplos presentes na literatura científica reforçam o argumento de que o desenvolvimento do currículo exige dos professores que tenham como ponto de partida as realidades dos contextos locais e dos alunos reais, isto é, que usem as suas condições de agência para conceber e desenvolver projetos adequados à formação dos seus alunos. Isso é essencial à tomada de decisões curriculares dos professores, mobilizando-os para processos de contextualização curricular (FERNANDES et al., 2013). Tais práticas, contudo, só podem ocorrer mediante a existência de autonomia pedagógica e curricular dos professores e de condições para a sua concretização.

À semelhança de vários países (EURYDICE, 2007), Portugal tem apontado nos discursos políticos de educação para a autonomia das escolas. Esse discurso que, como já foi referido, circula desde 1989 (PORTUGAL, 1989) e sobretudo a partir de 1998 (PORTUGAL, 1998), veiculou um entendimento de autonomia como

[...] o poder reconhecido à escola [...] de tomar decisões nos domínios estratégico, pedagógico, administrativo, financeiro e organizacional, no quadro do seu projecto educativo e em função das competências e dos meios que lhe estão consignados. (Capítulo I, artigo 3º).

Neste último diploma legal, ainda que, por um lado, se possa considerar que é conferida às escolas alguma liberdade na tomada de decisão relativamente ao modo como se organizam e desenvolvem a ação educativa e pedagógica, por outro, o texto é pouco 
específico quanto à autonomia docente. Percebe-se que são ainda muito pouco enunciados corredores de liberdade para uma agência dos professores.

A agência dos professores, nomeadamente no que diz respeito à autonomia curricular, emerge nos discursos oficiais no final da década de 1990 com o Projeto de Gestão Flexível do Currículo para o Ensino Básico (Despacho n. ${ }^{\circ}$ 9590/99). Esse Projeto, generalizado após uma experiência piloto de quatro anos, teve como objetivo

[...] promover uma mudança gradual nas práticas de gestão curricular nas escolas do ensino básico, com vista a melhorar a eficácia da resposta educativa aos problemas surgidos da diversidade dos contextos escolares, fazer face à falta de domínio de competências elementares por parte de muitos alunos à saída da escolaridade obrigatória e, sobretudo assegurar que todos os alunos aprendam mais e de um modo mais significativo (in preâmbulo). (PORTUGAL, 1999).

Depreende-se desse discurso a intenção política de conceder às escolas e aos professores a possibilidade de flexibilizarem o currículo prescrito a nível nacional, realizando adaptações que possam gerar melhores aprendizagens dos alunos. Essa ideia é, aliás, corroborada no texto do anexo ao normativo, no qual se define a gestão flexível do currículo como

[...] a possibilidade de cada escola organizar e gerir autonomamente o processo de ensino/ aprendizagem, tomando como referência os saberes e as competências nucleares a desenvolver pelos alunos no final de cada ciclo e no final da escolaridade básica, adequando-o às necessidades diferenciadas de cada contexto escolar e podendo contemplar a introdução no currículo de componentes locais e regionais. (PORTUGAL, 1999).

Antevê-se nesse discurso político o anúncio de uma agência dos professores na construção de propostas curriculares flexíveis. Esta orientação está também alinhada ao Estatuto da Carreira dos Educadores de Infância e dos Professores dos Ensinos Básico e Secundário, criado em 1999 e revisto com regularidade, o qual constituiu uma marca importante na afırmação da agência docente. 0 artigo $5^{\circ}$ do Capítulo II desse documento consagra o direito dos professores de participação no processo educativo nos seguintes termos:

0 direito a participar na defınição das orientações pedagógicas ao nível do estabelecimento de ensino ou das suas estruturas de coordenação; 0 direito à autonomia técnica e científica e à liberdade de escolha dos métodos de ensino, das tecnologias e técnicas de educação e dos tipos de meios auxiliares de ensino mais adequados, no respeito pelo currículo nacional, pelos programas e pelas orientações programáticas curriculares ou pedagógicas em vigor. (PORTUGAL, 2013).

Para além dos direitos, também os deveres dos professores apontam para a necessidade de, na sua prática profissional, fazer uso da experiência e conhecimento que possuem no sentido de promover a aprendizagem dos seus alunos. É exemplo disso a alínea d) do Artigo $10^{\circ}$ do Estatuto da Carreira dos Educadores de Infância e dos Professores 
dos Ensinos Básico e Secundário, que atribui aos docentes o papel de "Organizar e gerir o processo de ensino-aprendizagem, adoptando estratégias de diferenciação pedagógica susceptiveis de responder às necessidades individuais dos alunos" (PORTUGAL, 2013). 0 mesmo diploma sugere que sejam estabelecidas relações de cooperação entre pares e com outros membros da comunidade educativa, incluindo-se nessa cooperação a partilha de materiais e o trabalho colaborativo (Capítulo II, Secção II, Artigo 10. Alínea c) e Capítulo II, Secção II, Artigo) 10-B, Alíneas d) e e)). Em síntese, essas orientações indiciam a valorização de modos de trabalho cooperativo (LEITE; PINTO, 2016; PINTO; LEITE, 2014) no desenvolvimento do processo de ensino-aprendizagem.

$\mathrm{Na}$ análise de discursos políticos em sua relação com práticas curriculares dos professores, é importante referir que a filosofia da flexibilização curricular se consolidou com a Reorganização Curricular do Ensino Básico (PORTUGAL, 2001), mantendose no discurso das políticas curriculares durante a primeira década dos anos 2000, a par de medidas de atribuição de autonomia às escolas, tendo sido abandonada em 2012 (PORTUGAL, 2012). Ainda no que diz respeito à autonomia das escolas, em 2007, foram estabelecidas (PORTUGAL, 2007) as condições para celebração dos contratos de autonomia das escolas, definindo seu âmbito em termos de: “a) Organização pedagógica; b) Organização curricular; c) Recursos humanos; d) Acção social escolar; e) Gestão estratégica, patrimonial, administrativa e financeira" (Artigo 50). Uma vez mais se identificam no discurso legal referências à capacidade das escolas para a tomada de decisão curricular, mas poucas ou nenhuma referência concreta ao exercício de agência dos professores na concretização de uma autonomia curricular. Essa mesma situação ocorreu quando, na revisão da legislação relativa ao regime de autonomia das escolas (PORTUGAL, 2008) o enfoque foi colocado na organização, gestão e administração escolar, sendo quase ausente a referência à componente curricular e pedagógico-didática dos professores.

Em 2017, o governo português, agora com uma nova orientação política e nova equipe, (re)lançou o projeto de autonomia e flexibilidade curricular dos ensinos básico e secundário (PORTUGAL, 2017), implementado na transição do século XX para o século XXI e interrompido em 2011/2012 (PORTUGAL, 2011, 2012). 0 discurso desse novo diploma político parece considerar as conclusões da investigação científica sobre a importância de as escolas e professores serem reconhecidos nos seus poderes de decisão curricular, mostrando quase total harmonia com as ideias que reconhecem a importância, quer da agência dos professores, quer da contextualização do currículo.

Em sintese, as possibilidades de agência docente, a autonomia dos professores e a tomada de decisão curricular parecem estar discursivamente contempladas em vários diplomas políticos que regulam a educação escolar em Portugal, sobretudo a partir da década 2000. Parece também ser possível inferir, a partir da literatura científica e dos discursos políticos, que se torna expectável que, no contexto da prática educativa, os professores façam uso da sua capacidade de ação e da autonomia curricular, mobilizando a sua experiência profissional e o conhecimento que têm dos contextos e dos seus alunos para a construção de ambientes de ensino-aprendizagem a eles adequados. 


\section{O desenho do estudo}

Tendo em conta a possível relação entre o exercício de agência dos professores na configuração de práticas de contextualização curricular e o sucesso dos alunos, o estudo apresentado neste artigo teve como objetivo conhecer e caracterizar práticas de contextualização e dinâmicas inerentes a essas práticas em três escolas de ensino básico e secundário do norte de Portugal. Essas escolas foram escolhidas por ocuparem posições elevadas no ranking ${ }^{2}$ dos resultados escolares. As escolas pertencem a contextos diferenciados: uma delas situa-se no centro urbano de uma das principais cidades de Portugal; outra está localizada num meio rural; a terceira está situada numa cidade de pequeno porte. 0 nível socioeconômico dos alunos que frequentam as escolas, embora diverso, é globalmente médio. Participaram do estudo professores das disciplinas de português; história; matemática, biologia e geologia; e física e química. Foram realizados cinco grupos focais (BARBOUR; KITZINGER, 1999; HOPF, 2004) em cada escola (uma por disciplina), com três professores cada, num total de 45 participantes. Os professores entrevistados são maioritariamente do sexo feminino (38), sendo apenas sete professores do sexo masculino. Dentre os 45 professores, quatorze ocupavam o cargo de coordenadores de departamento, sendo quatro do sexo masculino e dez do sexo feminino. A faixa etária desses professores situa-se entre 40 e 60 anos de idade. Todos os professores tinham mais de dez anos de experiência docente. Para efeitos de anonimato e confidencialidade dos dados, a cada professor entrevistado foi atribuído um código constituído pela letra $\mathrm{P}$ (professor), a sigla da disciplina que lecciona ( $\mathrm{P}$ - Português; $\mathrm{M}$ - Matemática; $\mathrm{H}$ História; FQ - Física e Química; BG - Biologia e Geologia), e um algarismo.

As entrevistas foram transcritas e analisadas pela técnica de análise de conteúdo (BARDIN, 2011; AMAD0, 2013), com recurso ao software NVivo 11. Os discursos dos professores foram organizados com base nas seguintes categorias: intenções/motivações para a contextualização curricular; práticas de contextualização curricular, e dentro desta, as subcategorias: práticas utilizadas; dificuldades sentidas na contextualização curricular. As categorias foram cruzadas entre si, possibilitando análises mais aprofundadas.

\section{Os corredores de liberdade docente: uma interpretação de relatos de professores}

Tal como foi anteriormente afirmado, a leitura e análise dos vários discursos políticos faz crer em possibilidades e espaços de autonomia dos professores ou, em outras palavras, na existência de corredores de liberdade que os professores podem percorrer em suas práticas docentes. Tais corredores de liberdade são espaços e tempos nos quais os professores se assumem como decisores curriculares, planejando ações e agindo de acordo com aquilo que acreditam ser a melhor opção, fazendo muitas vezes uso do saber construído ao longo da carreira e do conhecimento adquirido, quer do contexto em que

2- 0 ranking das escolas é divulgado pela comunicação social e consiste numa listagem das escolas construída a partir dos resultados obtidos pelos alunos nas provas finais de $9^{\circ}$ ano (ano final do ensino básico) e $11 \% 12^{\circ}$ ano (anos finais do ensino secundário). 
atuam, quer dos alunos a quem se dirige o currículo e com os quais o desenvolvem. Seria, portanto, expectável que, nos seus relatos sobre as dinâmicas diárias e sobre as práticas de contextualização curricular, esses momentos fossem referidos como usuais. No entanto, essas práticas convivem com uma realidade e com exigências que dificultam a sua concretização.

Seguindo as categorias de análise identificadas, os discursos dos professores são apresentados com ênfase, por um lado, nas intenções/motivações para práticas de contextualização curricular e, por outro lado, nas práticas de contextualização curricular utilizadas, assim como nas dificuldades e obstáculos que os professores encontram para a sua concretização, isto é, para o uso da sua agência. Considerando essa situação, questionam-se os corredores de liberdade dos professores e o modo como são percorridos.

Importa referir que os professores envolvidos neste estudo valorizaram e reconheceram o potencial das estratégias de contextualização curricular, de tal modo que afirmaram procurar oportunidades para recorrer a estas práticas. A quase totalidade dos professores entrevistados assumiu que, sempre que possível, opta por abordagens pedagógico-didáticas não tradicionais, que recorrem a princípios de contextualização do currículo. Exemplo disso foram as referências ao fato de partirem de diferentes inputs que sabem ser os mais adequados para motivar seus alunos e promover a aprendizagem. São exemplo os discursos:

Tentar interessá-los nos conteúdos que tenho que obrigatoriamente transmitir... também não me não quero cingir só aquilo que o programa me obriga. Quero-lhes abrir os horizontes [...] têm que se arranjar meios para se conseguir isso, não é? (P_H1).

[...] há sempre referências que faço a aspetos culturais [...] lá está, porque é significativo, porque é para os ajudar. (P_P1).

[...] há a aplicação de determinado conteúdo a exemplos de alguma forma ligados ao dia a dia... tentar usar a Matemática para, de alguma forma, resolver isso que é o nosso problema do dia a dia. (P_M1).

Às vezes até - porque eu sei que eles amam o futebol - digo assim: “Então vamos lá analisar o pontapé que este jogador deu”... na Química... numa sopa que eles comam [...] E os miúdos ficam agarrados. (P_FQ2).

Eles até são, às vezes, os primeiros "Oh professora, viu? Houve um sismo". E nós vamos ao computador e vamos ver, por exemplo, o telejornal... e passamos a notícia, e depois eles analisam logo a notícia... Portanto, analisamos, aproveito sempre... (P_BG2).

0 testemunho desses professores revela que, quando têm oportunidade para tal, são capazes e se valem da sua expertise para oferecer aos seus alunos um ambiente de ensino-aprendizagem mais adequado, interessante e potencialmente mais bem-sucedido. Ou seja, a ação dos professores ouvidos neste estudo está associada ao conceito de agência 
(PRIESTLEY, 2011), na medida em que os professores procuram, dentro das condições que lhes são oferecidas e das possibilidades que existem nos contextos educativos, agir de forma a promover mudanças e melhorias nas práticas curriculares. Essa tentativa constante de adequar as práticas revela que os professores têm um conhecimento profundo dos conteúdos curriculares e das características dos seus alunos. Mostra ainda que, tal como Biesta e Tedder (2007) argumentam, esses professores possuem a qualidade de agência ao atuar dentro de espaços, tempos e contextos, procurando oportunidades para adotar estratégias diversificadas de desenvolver os programas de modos menos tradicionais.

Os relatos apresentados, por darem conta das tentativas e iniciativas de professores de adequar as suas práticas curriculares tendo em conta os interesses e necessidades dos seus alunos, corroboram o argumento defendido pela investigação científica: os alunos se beneficiam de práticas que aproximam conteúdos curriculares abstratos de realidades por eles vividas e experienciadas (HARTNELL-YOUNG; VETERE, 2008; COOK-SATHER, 2006; SOUTO-MANNING, 2008; KING, BELLOCHI, RITCHIE, 2007; YAMAUCHI, 2003; GILLESPIE, 2002; KALBCH, FORESTER, 2006). De fato, professores de todas as disciplinas dão exemplos e se referem a momentos em que recorreram à contextualização curricular, conscientes de que esse tipo de abordagem é motivadora e apreciada pelos seus alunos. Veja-se o discurso de professores de português e história, duas disciplinas com uma matriz curricular muito específica:

Vou-lhe dar um exemplo em termos práticos [...] 0 ano passado, tivemos uma noite medieval [...] nós associámo-nos e recriámos os Jogos Olímpicos à maneira Grega [...] Portanto, estamos a envolver outras disciplinas, outras atividades, outras competências, e eu acho que dessa diferença toda é que nasce a riqueza, não é? (P_H2).

[...] num dia de primavera puderam fazer fotografias... creio que foi uma boa maneira de os motivar para a leitura do romance [...] Por exemplo, com os Maias é muito fácil de fazer sempre o paralelo com a atualidade. Quanto mais não seja pelas figuras caricaturais que aparecem no romance que, muitas delas, bem ou mal ainda encontramos na sociedade dos nossos dias. (P_P2).

0 testemunho de professores de biologia e geologia e de física e química, disciplinas que têm uma especificidade prática, vai no mesmo sentido, como se depreende dos seguintes depoimentos:

Hoje eu cheguei a casa à 1h30, liguei a televisão e estava a dar o Jornal da Tarde. E o assunto era uma praga nas videiras do Douro. Hoje o meu assunto na aula foi sobre o controlo de pragas. Eu não vou arranjar uma situação fictícia. Pego numa situação real, e nós exploramos uma situação real. (P_BG2).

[...] cancro, de uma terapêutica qualquer sobre a imunidade... nós trazemos essa informação, nós partilhamos essa informação, e trabalhamo-la com os alunos para que eles sintam que nós não estamos fora do que é a realidade, o quotidiano. (P_BG1). 
Então, eu tento lançar sempre para o terreno, o mais possivel, esses desafios, fazê-los ver em redor, se um carro vai um bocadinho instável porque é que ele vai instável, como é que temos de pôr o carro naquela mecânica... Travar como é que funciona? Se o carro vai em combustão ou não sei quê? (P_FQ2).

[...] tentar que eles percebam melhor aquilo que eu quero. Que vejam uma simulação que eu na aula não consigo fazer. Há muitas coisas de Física... que eu não consigo fazer. E à simulação eles reagem muito bem. (P_FQ1),

Também os professores de matemática, disciplina a que muitas vezes é associado um caráter mais abstrato, sobretudo no $12^{\circ}$ ano, dão conta de práticas curriculares de contextualização:

Fazemos também diferenciação a este nível. 0 tipo de questões, por vezes não é a mesma questão para todos os alunos. A extensão do próprio trabalho... sou capaz de fazer dois tipos de testes. (P_M2).

Nós cumprimos, tentamos adequar as estratégias, fazer atividades e tarefas que permitam que os alunos desenvolvam as capacidades... e depois também tarefas, também as fazemos e articulamos de modo a por coisas que também se ajustem àquilo que nos é pedido. (P_M1).

0 discurso dos professores dá conta do seu poder de agência, revelando momentos e estratégias que usam com base na sua experiência e conhecimentos e no que acreditam ser mais adequado aos seus alunos, dentro das possibilidades que encontram no quotidiano escolar. Ou seja, os relatos dos professores entrevistados mostram uma predisposição para se assumirem como decisores curriculares (BEANE, 2003; LEITE; FERNANDES 2010), adequando e adaptando os conteúdos do currículo prescrito a nível nacional para melhor corresponderem às necessidades e características dos seus alunos, numa tentativa de promover o sucesso (LEITE; FERNANDES, 2002; HARTNELL-YOUNG, VETERE, 2008; DOYLE, 2009; COOK-SATHER, 2006; SOUTO-MANNING, 2008). Mais uma vez, essa situação está em linha com outros estudos que apontam vantagens do recurso a práticas de contextualização, localmente planejadas (YAMAUCHI, 2003; GILLESPIE, 2002; PALIWAL; SUBRAMANIAM, 2006; HARTNELL-YOUNG; VETERE, 2008). No entanto, apesar de os discursos apresentados darem conta do seu poder de agência, os professores entrevistados revelam também um quotidiano escolar no qual iniciativas desse calibre se confrontam com condições pouco propícias a uma prática autônoma e exigências externas que os levam a seguir lógicas de performatividade. São vários os aspectos referidos pelos professores ouvidos neste estudo, mas a maioria está relacionada com os programas curriculares defınidos a nível nacional pelo Ministério da Educação.

Associados aos programas prescritos para o ensino das várias disciplinas, encontramos diferentes constrangimentos à liberdade e autonomia docente. Por exemplo, professores de matemática e de física e química referem desfasamentos nos programas das duas disciplinas que os impedem, muitas vezes, de desenvolver atividades em conjunto, atividades de 
articulação curricular, que poderiam conferir maior significado e mostrar a utilidade e transversalidade dos conteúdos abstratos que lecionam. São exemplos disso os depoimentos:

[...] há conteúdos que eles até se cruzam, mas a necessidade que a Física tem, por exemplo, de leccionar determinado conteúdo, é completamente desfasada daquilo que é o timing certo para a Matemática... por exemplo, a Física... precisa que os alunos saibam trigonometria... num momento em que eu estou apenas a começar a dá-la. (P_M1).

0 mesmo é verdade para a relação entre as disciplinas de biologia e geologia e de física e química,

É, mas é um bocadinho difícil quando nós, por exemplo, neste caso particular, nós falamos destes assuntos no $10^{\circ}$ e eles são dados no $11^{\circ}$ na Física-Química, no ano seguinte. (P_BG1).

Portanto, há desfasamentos no programa, a transversalidade do programa não é... é muito pouca e quando existe é desfasada temporalmente. Portanto, nesse aspeto acho que não houve essa preocupação nos programas. (P_BG2).

Verifica-se, portanto, que, a articulação horizontal e vertical do currículo valorizadas nos discursos políticos que orientam a prática docente são difíceis de se concretizarem no contexto da prática. Ou seja, apesar de a investigação científica (BEANE, 2003; FORMOSINHO; MACHADO, 2008) mostrar as potencialidades desse tipo de prática curricular, provando que os alunos se beneficiam de um currículo desenvolvido de modo transversal e multifacetado, a sua concretização convive com a existência de currículos implementados numa lógica top-down, que se revelam muitas vezes desajustados aos contextos e aos alunos reais.

Outro aspecto relacionado com os programas curriculares que constrange o poder de agência na prática docente diz respeito ao volume de conteúdos e à extensão dos programas. Essa situação, aliada à existência de provas de exame finais para os alunos, dificulta muitas vezes a implementação de abordagens inovadoras, remetendo os professores a práticas mais transmissivas e de treinamento dos alunos para serem bemsucedidos numa avaliação uniformizante. Isso foi declarado por vários professores ouvidos nas escolas consideradas neste estudo. 0 argumento comum é que, apesar das tentativas e das iniciativas a que se dedicam para trabalhar o currículo de forma diversificada, os professores se sentem constrangidos e limitados pelas condições envolventes:

Eu acho que é mais pelo programa também que nós temos uma carga nas costas que é "tens que dar isto, tens que dar aquilo", e tentar fugir ao programa, tornear as dificuldades, eu acho que é muito complicado. Não é fácil. (P_FQ1).

Mas nós relativamente ao currículo temos muito pouca margem de manobra. Porque se estamos sujeitos a uma avaliação externa com o peso que tem a Biologia e Geologia... (P_BG1). 
Porque nós sabemos que se conseguirmos ter mais tempo, nós conseguimos pegar numa tarefa, explorá-la muito mais. Mas como nós temos o tempo controlado... Se eu não tivesse um programa para cumprir, eu poderia fazer as coisas de outra forma; eu poderia adotar outras metodologias, outras estratégias... (P_M2).

[...] o programa é enorme na minha disciplina, portanto, há uma planificação que deve ser cumprida com algum rigor senão não conseguimos cumprir o programa. (P_BG2).

[...] o tempo para se gerir um programa que é, depois, sujeito a um exame nacional, não nos permite, realmente, muitas dispersões. (P_P2).

Os excertos mostram que os professores enfrentam, diariamente, exigências e obstáculos que os levam a abandonar práticas curriculares consideradas mais criativas e diferenciadas, por terem em conta os interesses dos alunos e características do contexto, para assumirem processos de ensino-aprendizagem mais tradicionais, seguindo modos pedagógico-didáticos transmissivos e mais uniformizadores. Ou seja, os professores sofrem pressões que os empurram para a performatividade (BALL, 2003, 2004; PERRYMAN, 2006, 2007) advinda de uma prática que tem sido criticada por não responder aos alunos na sua individualidade, e por olhar o grupo como um todo uniforme.

Outro aspecto referido pelos professores como limitação a práticas de contextualização curricular diz respeito ao modo como os tempos letivos estão organizados e ao número de alunos por turma, tal como é expresso no seguinte depoimento:

[...] temos que fazer a gestão do tempo em função do que temos. 0 problema é termos perdido carga horária. E agora vamos perder outra coisa, que é o aumento do número de alunos por turma. (P_H2).

Importa referir que a definição da carga horária de cada disciplina, bem como a definição do número de alunos por turma são de responsabilidade do Ministério da Educação. Em 2012, uma política ministerial (PORTUGAL, 2012) aumentou esse número, o que, segundo os professores, dificultou a personalização do ensino e a contextualização do currículo, dificultando a gestão de alunos com diferentes ritmos e necessidades. A redução da carga horária semanal de algumas disciplinas tem agravado essa situação.

Em síntese, estes dados revelam que a autonomia conferida às escolas pela legislação (PORTUGAL, 1998, 2008) encontra limites e oposições decorrentes dos exames finais a que são sujeitos os alunos a nível nacional e que optam pela uniformidade. Este fato fica claro no discurso dos professores, por exemplo:

Porque, quer queiramos ou não, por muito que a gente leia o que é a Gestão Flexível do Currículo... vai-se chegar ao exame nacional e eles têm que saber aqueles temas que estão no currículo, eles têm que saber aqueles conteúdos eles têm que saber. (P_BG2). 
Em relação à escola ter hipótese de escolher as obras. É assim, isso dá uma liberdade à escola que depois é tirada se calhar na altura dos exames, não é? Porque os exames depois procuram uniformizar... os exames depois focam-se naqueles conteúdos do programa. (P_P3).

[...] estamos limitados àqueles objetivos mais específicos ou específicos e que têm que se cumprir quase objetivo a objetivo, porque são depois testados e nós temos que... não podemos fugir muito disso. (P_FQ1).

Os discursos dos professores ouvidos neste estudo são consistentes e coerentes, verificando-se uma transversalidade nos testemunhos sobre as práticas curriculares que desenvolvem. De fato, independentemente das distintas características de gênero, idade, escola onde é exercida a docência ou disciplina lecionada, os relatos desses professores mostram que suas práticas são suportadas em crenças e ideologias educacionais comuns. Apesar disso, esses relatos também mostram que, tal como teorizam Biesta e Tedder (2007), a agência não é uma qualidade que os indivíduos possuem por si só, isto é, não ocorre independentemente dos contextos, circunstâncias e condições existentes. A agência é, sim, algo que os professores fazem em espaços-tempos existentes dentro determinados contextos, os quais por vezes dificultam a capacidade de ação, limitam as possibilidades e, consequentemente, comprometem a mudança que se pretende operar. A agência não pode ser entendida como uma escolha, uma forma de atuar que ocorre somente por vontade ou iniciativa dos professores, estando isenta de influências contextuais ou imune às condições envolventes, tal como alertado pela literatura (PRIESTLEY, 2011; PRIESTLEY; BIESTA; ROBINSON, 2015).

\section{Práticas curriculares de professores: um balanço de possibilidades e de tensões}

Este artigo discute as práticas de agência dos professores e as condicionantes que as afetam. Apesar da clara intenção dos professores de adequar suas práticas aos contextos e aos alunos e, sempre que possível, fazer uso da sua capacidade de tomada de decisão curricular (LEITE, 2003, 2006; LEITE; FERNANDES, 2010), os professores ouvidos neste estudo relatam algumas limitações sentidas, as quais que se derivam não apenas das condições do dia a dia de suas escolas, mas, sobretudo, de condicionantes impostas por políticas públicas de educação (BALL, 2004).

A análise dos discursos de professores de três escolas do norte de Portugal permitiu constatar que eles vivem quotidianos profissionais marcados por tensões de natureza diversa que os empurram para práticas curriculares quase sempre prisioneiras de lógicas prescritivas e performativas, das quais dificilmente conseguem fugir. Essa realidade parece ser contraditória com a visão de investigadores do campo do currículo e do trabalho docente (LEITE; FERNANDES, 2010; FERNANDES et al., 2013; FERNANDES; FIGUEIRED0, 2012; LEITE; DELGADO, 2012; ROLDÃO, 2010; ZIBETTI; REBELLO DE SOUZA, 2010; PRIESTLEY, 2011; PRIESTLEY; BIESTA; ROBINSON, 2015) que têm defendido a importância de os 
professores se assumirem como decisores do currículo fazendo uso dos corredores de liberdade de que dispõem.

A análise de discursos políticos - legislação reguladora da autonomia das escolas, estatuto da carreira docente, entre outros - mostra alguma incoerência entre posições que reconhecem a necessidade de os professores serem providos de poder para a tomada de decisão sobre o desenvolvimento do currículo e as condições que esses profissionais encontram no contexto da sua prática docente. Os dados desta investigação mostram um quotidiano de luta entre o que consideram ser o mais adequado para os seus alunos e para os contextos em que intervêm e o que são impelidos a fazer como resposta às demandas centrais.

Em que pese essa tendência dos dados, os professores entrevistados, na sua maioria, consideram essencial que o currículo seja contextualizado aos contextos e situações reais que caracterizam os alunos com que diariamente interagem para lhes oferecerem experiências de ensino-aprendizagem significativas e bem-sucedidas. Os seus discursos deixam ainda transparecer a ideia de que, enquanto docentes, procuram no seu dia a dia ir além de práticas tradicionais buscando, dentro das condicionantes existentes e das possibilidades de agência que têm, fazer mais e melhor pelos seus alunos. As condicionantes identificadas relacionam-se sobretudo com lógicas de performatividade (BALL, 2003, 2004; PERRYMAN, 2006, 2007) a que têm de responder, resultantes de políticas educativas e curriculares que colocam ênfase em resultados escolares e na excelência acadêmica. Essas medidas, pensadas por agentes e decisores do macro sistema, são muitas vezes vividas com um enorme distanciamento por parte dos agentes educativos locais, nomeadamente os professores, mas também pelos pais e outros elementos da comunidade, resultando em sentimentos de descrença e numa interpretação desfasada entre expectativas e possibilidades concretas de sua realização.

Pode-se concluir, então, que os dados obtidos neste estudo corroboram outras investigações que dão conta da inexistência de uma correlação entre o mundo da retórica, da política e do discurso, e o mundo da prática, das escolas e do trabalho docente. Com efeito, os relatos dos professores entrevistados trazem à tona a incoerência existente entre o que é exigido de professores e alunos como fruto do processo de ensino-aprendizagem e as recomendações e discursos que defendem a adoção de metodologias de ensino diversificadas. Mais precisamente, os discursos mostram que as condições de trabalho dos professores, aliadas às questões de avaliação, especificamente a exigência de um exame final, dificultam e limitam a autonomia no desenvolvimento de práticas curriculares inovadoras e contextualizadas aos estilos, interesses e ritmos de aprendizagens dos alunos.

Estas considerações reforçam a ideia já defendida de que o desfasamento entre orientações curriculares, exigências e metas traçadas e as condições para a sua concretização é revelador de uma falta de complementaridade entre os diferentes decisores do currículo que atuam a nível macro, médio e micro. Essa linha de pensamento é mais uma vez reforçada pelos dados que mostram que, no campo da educação, os discursos políticos e as orientações para a sua concretização se contrariam. Por exemplo, a extensão dos currículos, que devem ser cumpridos rigorosamente, e a sua avaliação por meio de exames finais com ponderações elevadas não se coadunam com o tempo e dedicação necessários para implementação de práticas curriculares diferenciadas e diversificadas e processos 
de avaliação formativa. Por isso, essa situação inibe a liberdade de ação e decisão dos docentes, colocando-os perante um conflito entre o que acreditam ser o procedimento mais adequado para promover uma formação global dos alunos e a necessidade de cumprimento de um programa a ser medido numa prova final. É, então, possível afirmar que os professores percorrem corredores de liberdade estreitos, limitados por paredes assentes em demandas externas.

A ambivalência entre os discursos curriculares e as (im)possibilidades de agência dos professores, evidenciada pelos dados desta investigação, leva-nos a questionar como a escola e os professores poderão servir, ao mesmo tempo e com a mesma dedicação, a propósitos não conciliáveis?

\section{Referências}

AMAD0, João. Manual de investigação qualitativa em educação. Coimbra: Universidade de Coimbra, 2013.

BALL, Stephen. Performatividade, privatização e o pós-estado do bem-estar. Educação \& Sociedade, Campinas, v. 25, n. 89, p. 1105-1126, set./dez. 2004

BALL, Stephen. The teacher's soul and the terrors of performativity. Journal of Education Policy, Reino Unido, v. 18, n.2, p. 215-228, nov. 2003.

BARBOUR, Rosaline; KITZINGER, Jenny. Developing focus group research: politics, theory and practice. London: Sage, 1999.

BARDIN, Laurence. Análise de conteúdo. Lisbon: Edições 70. 2011.

BEANE, James. Integração curricular: a essência de uma escola democrática. Currículo sem Fronteiras, v. 3, n. 2, p. 91-110, jul./dez. 2003.

BIESTA, Gert; TEDDER, Michael. Agency and learning in the lifecourse: towards an ecological perspective. Studies in the Education of Adults, Reino Unido, v. 39, n. 2, p. 132-149, 2007.

BUENDÍA, Edward; GITLIN, Andre; DOUBIA, Fodé. Working the pedagogical borderlands: an African critical pedagogy. Curriculum Inquiry, Reino Unido, v. 33, n. 3, p. 291-320, Sep. 2003.

BUSTOS-OROSA, Alicia. Inquiring into Filipino teachers' conceptions of good teaching: a qualitative research study. The Asia-Pacific Education Researcher, Reino Unido, v. 17, n. 2, p. 173-189, Dec. 2008.

COMISSÃO EUROPEIA. Comunicação da Comissão ao Parlamento Europeu, ao Conselho, ao Comité Económico e Social Europeu e ao Comité das Regiões: desenvolvimento das escolas e um ensino da excelência para um melhor começo de vida. [S. I.: s. n.], 2017. Disponível em: <http://eur-lex.europa.eu/legal-content/PT/TXT/HT ML/?uri=CELEX:52017DC0248\&qid=1507286893906\&from=EN>. Acesso em: 1 out. 2017.

COOK-SATHER, Alison. Sound, presence, and power: "student voice" in educational research and reform. Curriculum Inquiry, Reino Unido, v. 36, n. 4, p. 359-390, 2006.

DAVIES, Trevor. Creative teaching and learning in Europe: promoting a new paradigm. Curriculum Journal, Reino Unido, v. 17, n. 1, p. 37-57, Feb. 2006. 
DOYLE, Walter. Situated practice: a reflection on person-centered classroom management. Theory into Practice, Reino Unido, v. 48, n. 2, p. 156-159, out. 2009.

EURYDICE. School autonomy in Europe: policies and measures. [S; I.]: European Commission, 2007. Disponível em: <http://eacea.ec.europa.eu/education/eurydice/documents/thematic_reports/090EN.pdf> Acesso em: 2 out. 2015.

FERNANDES, Preciosa; FIGUEIREDO, Carla. Contextualização curricular: subsídios para novas significações. Revista Interacções, Lisboa, v. 8, n. 22, p. 163-177, 2012.

FERNANDES, Preciosa et al. Curricular contextualization: tracking the meanings of a concept. The AsiaPacific Education Researcher, Singapore, v. 22, n. 4, p. 417-425, Nov. 2013.

FORMOSINHO, Joaquim; MACHAD0, João. Currículo e organização: as equipas educativas como modelo de prática pedagógica. Currículo Sem Fronteiras, v. 8, n. 1, p. 5-16, jan./jun. 2008.

FRANCO, Maria. Práticas pedagógicas de ensinar-aprender: por entre resistências e resignações. Educação e Pesquisa, São Paulo, v. 41, n. 3, p. 601-614, jul./set. 2015.

GILLESPIE, Marilyn. EFF research principle: a contextualized approach to curriculum and instruction. EFF Research to Practice Note, v. 3, p. 2-8, 2002.

GRAINGER, Teresa; BARNES, Jonathon; SCOFFHAM, Stephen. A creative cocktail: creative teaching in initial teacher education. Journal of Education for Teaching, Reino Unido, v. 30, n. 3, p. 243-253, 2004.

HARTNELL-YOUNG, Elisabeth; VETERE, Frank. A means of personalizing learning: incorporating old and new literacies in the curriculum with mobile phones. Curriculum Journal, Reino Unido, v. 19, n. 4, p. 283-292, dez. 2008.

HOPF, Christel. Qualitative interviews: and overview. In: FLICK Uwe; KARDOLF Ernst; STEINKE, Ines (Ed.). A companion to qualitative research. London: Sage, 2004. p. 203-208.

KALBACH, Linda; FORESTER, Lyn. The world and the world: a lesson in critical literacy and its impact on student achievement and self-esteem. Curriculum and Teaching Dialogue, v. 8, n. 1-2, p. 69-82. 2006.

KING, Donna; BELLOCCHI, Alberto; RITCHIE, Stephen. M. Making connections: learning and teaching chemistry in context. Research in Science Education, Netherlands, v. 3, n. 3, p. 365-384, Nov. 2007.

KUMAR, Muthu; NATARAJAN, Uma. A problem-based learning model: showcasing an educational paradigm shift. Curriculum Journal, Reino Unido, v. 18, n. 1, p. 89-102, May 2007.

LEITE, Carlinda. Para uma escola curricularmente inteligente. Porto: ASA, 2003.

LEITE, Carlinda. Políticas de currículo em Portugal e (im)possibilidades da escola se assumir como uma instituição curricularmente inteligente. Currículo Sem Fronteiras, v. 6, n. 2, p. 67-81, jul./dez. 2006.

LEITE, Carlinda; DELGADO, Fátima. Práticas curriculares no ensino da matemática: perceções de alunos do 9. ${ }^{\circ}$ ano de escolaridade e sua relação com a contextualização curricular. Interacções, Lisboa, v. 8, n. 22, p. 163-177, 2012. 
LEITE, Carlinda; FERNANDES, Preciosa. Avaliação das aprendizagens dos alunos. Porto: ASA, 2002.

LEITE, Carlinda; FERNANDES, Preciosa. Desafios aos professores na construção de mudanças educacionais e curriculares: que possibilidades e que constrangimentos. Educação, Porto Alegre, v. 33, n. 3, p. 198-204, set./dez. 2010.

LEITE, Carlinda; PINTO, Carmem. 0 trabalho colaborativo entre os professores no quotidiano escolar. Revista Educação, Sociedade \& Culturas, Porto, n. 48, p. 69-91, 2016.

PALIWAL, Rashmi, SUBRAMANIAM, C. Contextualising the curriculum. Contemporary Education Dialogue, v. 4, n. 1, p. 25-51, jul. 2006.

PERRYMAN, Jane. Inspection and emotion. Cambridge Journal of Education, Reino Unido, v. 37, n. 2, p. 173-190, jun. 2007.

PERRYMAN, Jane. Panoptic performativity and school inspection regimes: disciplinary mechanisms and life under special measures. Journal of Education Policy, Reino Unido, v. 21, n. 2, p. 147-161, ago. 2006.

PINTO, Carmem; LEITE, Carlinda. Trabalho colaborativo: um conceito polissémico. Conjectura, Caxias do Sul, v. 19, n. 3, p. 143-170, set./dez. 2014.

PORTUGAL. Decreto-lei nº 6/2001. Lisboa: [s. n.], 2001. Disponível em: <https://dre.tretas.org/dre/129231/ decreto-lei-6-2001-de-18-de-janeiro>. Acesso em: 29 set. 2017.

PORTUGAL. Decreto-lei no 43/1989, de 3 de fevereiro 1989. Lisboa: [s. n.], 1989. Disponível em: <http:// www.ige.min-edu.pt/upload/GTAA/DL_43_89.pdf>. Acesso em: 29 set. 2017.

PORTUGAL. Decreto-lei $n^{0}$ 75/2008 de 22 de abril. Lisboa: [s. n.], 2008. Disponível em: <https://dre.pt/ application/file/a/249886> . Acesso em: 29 set. 2017.

PORTUGAL. Decreto-lei no 115-A/98 de 4 de maio 1998. Lisboa: [s. n.], 1998. Disponível em: <http://www. ige.min-edu.pt/upload/Legisla\%C3\%A7\%C3\%A30/Dec_Lei_115-A_98.pdf>. Acesso em: 30 jan. 2013.

PORTUGAL. Despacho n. ${ }^{0}$ 5106-A/2012. Lisboa: [s. n.], 2012. Disponível em: <https://www.portaldasescolas. pt/imageserver/plumtree/portal/matnet/Despacho_5106A_2012.pdf>. Acesso em: 29 set. 2017.

PORTUGAL. Despacho n. ${ }^{\circ}$ 5908/2017. Lisboa: [s. n.], 2017. Disponível em: <https://dre.pt/application/ file/a/107635109>. Acesso em: 29 set. 2017.

PORTUGAL. Despacho n. ${ }^{\circ}$ 9590/99 de 14 de maio. Lisboa: [s. n.], 1999.

PORTUGAL. Despacho no. 17169/2011 de 12 de dezembro. Lisboa: [s. n.], 2011. Disponível em: <https://www. dge.mec.pt/sites/default/files/Basico/Legislacao/despacho_17169_2011.pdf>. Acesso em: 29 mar. 2013.

PORTUGAL. Estatuto da carreira dos educadores de infância e dos professores dos ensinos básico e secundário. Lisboa: [s. n.], 2013. Disponível em: <http://www.spn.pt/Media/Default/Info/7000/300/30/1/ ecd_consolidado_novembro2013.pdf>. Acesso em: 29 set. 2017. 
PORTUGAL. Portaria 1260/2007. Lisboa: [s. n.], 2007. Disponível em: < https://espacoseducativos. wordpress. com/2007/09/27/portaria-n\%C2\%BA-12602007-dr-n\%C2\%BA-186-serie-i-de-2007-09-26/>. Acesso em: 29 set. 2017.

PRIESTLEY, Mark. Schools, teachers, and curriculum change: a balancing act?. Journal of Educational Change, Netherlands, v. 12, n. 1, p. 1-23, fev. 2011.

PRIESTLEY, Mark; BIESTA, Gert; ROBINSON, Sarah. Teacher agency: what is it and why does it matter? In: KNEYBER, René; EVERS, Jelmer (Ed.). Flip the system: changing education from the bottom up. London: Routledge. 2015. p. 134-148.

ROLDÃO, Maria do Céu. Ensinar e aprender: o saber e o agir distintivos do profissional docente. In: TEODORA Romilda; BEHRENS, Marilda Aparecida (Org.). Formação do professor: profissionalidade, pesquisa e cultura escolar. Curitiba: Champagnat; PUCPR, 2010. p. 25-42.

SOUTO-MANNING, Mariana. Linking the words and the worlds through curriculum integration. Journal of Thought, California, v. 43, n.1/2, p. 95-103, 2008.

YAMAUCHI, Lois. Making school relevant for at-risk students: the wai'anae high school hawaiian studies program. Journal of Education for Students Placed At-risk, Reino Unido, v. 8, n. 4, p. 379-390. 2003.

ZIBETTI, Marli; REBELLO DE SOUZA, Marilene. A dimensão criadora no trabalho docente: subsídios para a formação de professores alfabetizadores. Educação e Pesquisa, São Paulo, v.36, n. 2, p. 459-473, maio/ ago. 2010.

Recebido em: 09.01.2018

Modificações em: 17.09.2018

Aprovado em: 28.09.2018

Carla Figueiredo é investigadora da Faculdade de Psicologia e de Ciências da Educação da Universidade do Porto. Participou de vários projetos de investigação. É autora e coautora de artigos, livros e capítulos de livro sobre avaliação, currículo e educação.

Carlinda Leite é professora catedrática na Faculdade de Psicologia e de Ciências da Educação da Universidade do Porto. Coordenou vários projetos de investigação. É autora e coautora de artigos, livros e capítulos de livro sobre currículo e educação.

Preciosa Fernandes é professora auxiliar na Faculdade de Psicologia e de Ciências da Educação da Universidade do Porto. Participou de vários projetos de investigação. É autora e coautora de vários artigos, livros e capítulos de livro sobre currículo e educação. 